\title{
International Experience in Addressing the Environmental Impact of Public Urban Transport
}

\author{
Zh. Musatova, I. Skorobogatykh*, N. Perepelkin, A. Tsvetkova \\ Plekhanov Russian University of economics, Moscow, Russia \\ ${ }^{*}$ Corresponding author. Email: skorobogatykh.II@ rea.ru
}

\begin{abstract}
The paper aims to study the impacts of the transport complex in large cities to environmental pollution and health of the citizens of the large sites in the world, and in Moscow city. The systematic review approach was used to collect, analyse the research papers, as well as reports, and publications in open sources via using the key words of the topic of study. The original methodology of systematic review as main approach of desk research was developed. More than 100 papers were selected and analysed, and main trends in negative impact produced by transport complex to environment were discovered.
\end{abstract}

Keywords: Urban public transport, Metropolis, Environment, Marketing research, International Comparative analysis.

\section{INTRODUCTION}

The purpose of this study is to identify a set of factors arising from the development of public urban transport that have a significant negative impact on the environment and health of citizens in Russia's largest city, Moscow. The main research question is: how the impact of transport on the ecological situation and health of citizens is analyzed globally and in individual foreign countries, and what factors have the greatest impact? The object of the study is a complex system of public urban transport in Moscow, the subject of the study is the identification and assessment of the negative impact of the transport complex on the environment and health of citizens.

International experience of studying environmental impact of transport factors (From Urban Public Transport as well as individual and commercial transport modes) has a sufficient history. Practically since the appearance of the first motor vehicles, society began to worry about the negative effects of transport on the environment, although there was no understanding of environmental issues as such. Nevertheless, the study of the impact of transport systems on the environment is worth determining from there. Initial intuitive fears of innovation gradually began to be matched by emerging issues and problems of an organizational and psychological nature - fuel extraction, waste and spare parts disposal, the organization of traffic itself, popularization of the innovation, etc. - but as society developed, ideas of collective social responsibility developed, and most importantly the rapid growth of passenger and freight mobility around the world widened the understanding of transport's role as a source of pollutants and their multiple detrimental

With the development of the industrial and then information society and the understanding of global ecological linkages on the planet and the synergistic effects of all types of pollution on the quality of life in major cities in virtually every region, increasing attention has been paid to the extent to which transport improvements affect other areas of life. In the situation of the dramatic growth of personal and commercial cars, the negative impact of the transport into environment and health in the large sites had been increased. Situation become more dramatic during the pandemic of COVID19. Therefore, one of the main problems is to study the level of competitiveness of the Urban Public Transport instead of the use of personal cars, and secondly to study the environmental impacts of transport complex. [1]

\section{METHODOLOGY}

The research methodology describes a desk research of existing publications, research reports and other documents that contain material on the issues of interest.

A systematic review method was used for the study, which differs from meta-analysis in its focus on 
identifying common trends without apparent inconsistencies. [2] The purpose of meta-analysis is usually to identify and further investigate differences in the results of existing research work on the same topic. [3] Thus, meta-analysis predominantly focuses on empirical research findings.

For the purposes of this study, other works are also important, so a systematic review approach is more justified. [4] A systematic review allows for the inclusion of all empirical and non-empirical studies, thus providing a comprehensive overview of the entire body of research on the selected issues. [5] For this study, in addition to academic articles, general media publications (mostly news, announcing or analyzing the implementation of specific transport management measures) have also been added to the source base for the review, as the issues in question are relevant and generate a significant response from a wide range of public organizations, governments, businesses and the public.

A fundamentally important feature of systematic reviews is the focus on identifying or creating a collective understanding of the processes or phenomena in question, based on a synthesis of theoretical and empirical research. Systematic review involves the use of comprehensible and reproducible processes to build a knowledge base by accumulating and analyzing data from different studies. [6,7]

The systematic review process is guided by the research question, which sets the logic and structure for the follow-up. Typically, at the initial research stage, the research question is formulated as broadly as possible and may be phrased as follows: what research in the field of interest has been conducted in the period of interest (perhaps from the first mention of the subject or from a point in time) to the current moment? In this way, access to the overall size and relevance of existing sources is delineated. [8] Further, the process of analysis within the overall topic identifies its individual elements to which attention has been particularly focused (either by the number of publications), or the request for similar publications in a recent time period (3-5-10) years is actualized. [9,10] An important aspect of the search activities is the use of the same concepts (keywords) for different databases at all stages of the search. Once the information is collected, it is analyzed, results and opinions that contradict the collective opinion of the majority of researchers are identified, and such sources are excluded to further form a common view of the issue.

The general methodology of systematic review has undergone some refinements in the framework of this study, considering the specifics of its objectives, as a result the general algorithm of review formation has the following steps:

1. Formulation of the goal of the analysis, setting the main research question.
2. Selection of databases and other sources to collect information.

3. Selecting key words and phrases to search for (initially and subsequently refined).

4. Identifying the temporal boundaries of data sources to update the analysis process.

5. Gathering information, checking for relevance.

6. Analyzing and systematizing the literature, eliminating critically inconsistent results, identifying common trends.

7. Formation of a text block based on the results of the analysis.

8. Assessment of possibilities to use the obtained results for application to the solution of similar research and practical tasks for the city of Moscow. This stage includes considering measures already implemented or being implemented at the moment of review preparation in the area of transport complex management aimed at improvement of environmental situation as well as evaluation of applicability of trends identified on stages 6-7 of the methodology for Moscow city (considering population size, transport complex development, weather and climate conditions).

9. Development of recommendations aimed at solving the tasks of the current study (considering the impact of transport factors on the environmental condition) in Moscow.

A systematic review of sources in desk research involves three stages: planning, execution, and reporting. The planning phase determines the aims of the study, the relevant resources to collect the information, and the keywords to search for. The implementation phase is then carried out, where information is extracted and its relevance and relevance assessed. In the final stage, the literature is analyzed, systematized and the results generated. Science Direct, EBSCO Host, and the search engines Google and Yandex were selected as search databases. The first two databases were selected based on the criteria of greatest coverage of sources, ease of searching within them, broad functionality and availability of access to them. The Russian search engine was added to the list of databases mainly in order to assess the applicability of foreign practices to the real situation in Moscow. The following keywords were selected: transport, public transport, ecology, city, public transport and ecology, public transport and health, transport and environment, transport and gas emissions. For the purposes of this study, the coverage of highly relevant sources was required, so the main period of analysis was chosen to be from 2015 to 2021, with a focus on the period 2019-2021. Information was collected between June and September 2021, and the researchers divided the data sources and concurrently formed a 
common dataset for further analysis. The analytical methodology described above can be iterative, the frequency of repetition can be set based on the rate of change in the external environment and technology, but on average a frequency of 1-2 years is recommended.

\section{ANALYSIS}

The relationship between transport and the environment is multi-dimensional. Some aspects are unknown and some new findings may lead to changes in environmental policy. Historically, transport has been associated with very few negative environmental impacts due to the modes of transport used and low levels of mobility. On the infrastructure side, the first comprehensive environmental regulation, the National Environmental Policy Act (HEPA) was passed in 1970 and required all federal agencies of the US Government to conduct environmental impact assessments of their actions. Since an agency such as the Department of Transportation manages all transportation infrastructure, this law influenced the perception of the Department's leadership and staff as to how the transportation system affects the environment. and environmental systems.

Logically, the stratification of the degree of attention given to the issue is based on the degree of development of society, its technogenic component and the priorities which are highly dependent on its economic development (Figure 1).

According to the data presented in Figure 1, it can be noted that since 2011 there has been a steady progression in the growth of public environmental preferences and their dominance over the economic preferences of society.

The growth of passenger and freight mobility has expanded the role of transport as a source of pollutant emissions and their multiple impacts on the environment.
According to Dr. Jean-Paul Rodrigo's submission1, there is the following typology of the environmental impacts of transport systems:

- Direct impacts. The direct effects of transport activities on the environment, where the causal relationship is generally clear and well understood. For example, noise and carbon monoxide emissions are known to have direct harmful effects.

- Indirect impacts. Secondary (or tertiary) impacts of transport activities on ecological systems. They often have more serious consequences than direct impacts, but the relationships involved are often misunderstood and more difficult to establish. For example, particulate matter, which is mainly the result of incomplete combustion in an internal combustion engine, is indirectly related to respiratory and cardiovascular problems because it contributes to such conditions, among other factors.

- Cumulative impacts. Additive, multiplicative or synergistic effects of transport activities. They consider a variety of direct and indirect effects on an ecosystem that are often unpredictable. Climate change, with its complex causes and consequences, is the combined effect of several natural and anthropogenic factors in which transport plays a role. Transport's share of global $\mathrm{CO} 2$ emissions is increasing. $22 \%$ of global CO2 emissions come from the transport sector, with a share of around $25 \%$ for advanced economies such as the US.

Transport activities support the growing need for passenger and freight mobility, especially in urban areas. But transport activities have led to increased motorization and congestion. As a result, the transport sector is increasingly linked to environmental issues, among which the most significant are recognized:

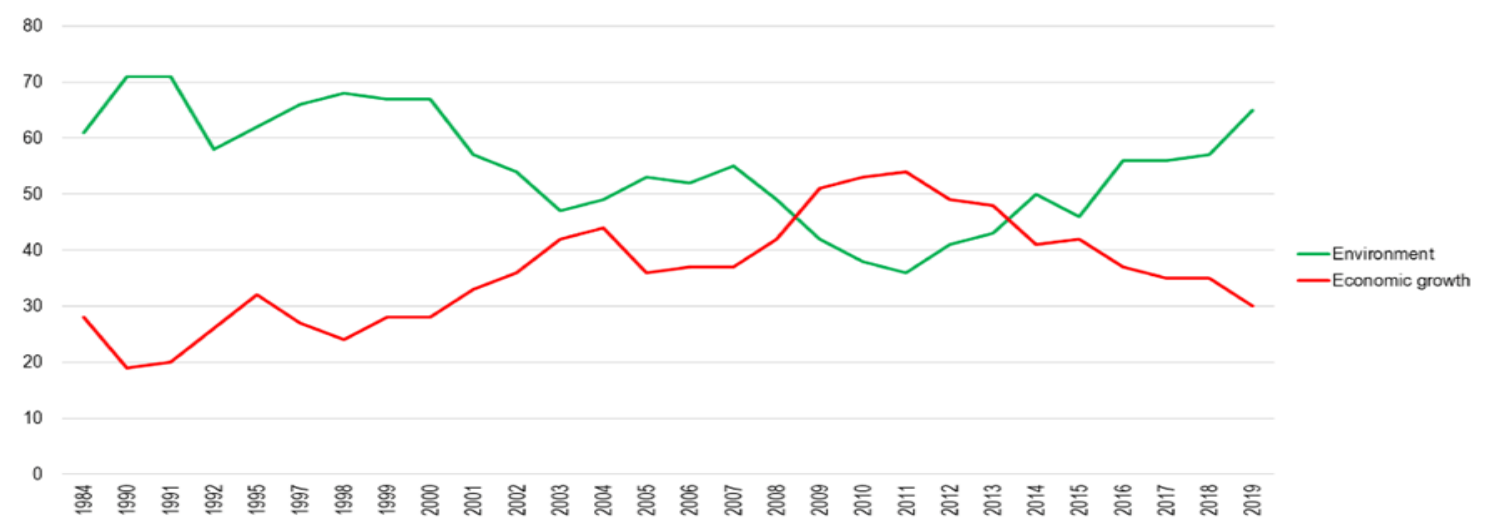

Figure 1 Public preferences for priority between the economy and the environment, 1984-2019 (Source: Electronic resource: 4.2 - Transportation and the Environment | The Geography of Transport Systems (transportgeography.org), access - free, access date: 01.06.2021) 
- Climate change caused by transport is down to temperature and other climatic changes due to global warming with an increasing greenhouse effect through the release of $\mathrm{CO} 2$ and fine dust together with heavy metals. Air quality. Road vehicles, marine engines, locomotives and aircraft are sources of pollution in the form of gas and particulate matter emissions. They affect air quality and are harmful to human health. The most common ones include lead $(\mathrm{Pb})$, carbon monoxide $(\mathrm{CO})$, nitrogen oxides (NOx), silicon tetrafluoride (SF6), benzene and volatile components (BTX), heavy metals (zinc, chromium, copper and cadmium) and particulates. (ash, dust). Lead emissions have declined substantially in recent decades since its use as an antiknock agent for gasoline has been banned in most countries worldwide since the 1980s. Only a few countries such as Myanmar, Iraq and North Korea still use leaded fuel.

- $\quad$ Noise. Represents the general impact of irregular and chaotic sounds on people and animals. Essentially, noise is unwanted sound. The acoustic measure of noise intensity is expressed in decibels $(\mathrm{dB})$ on a scale of 1 to $120 \mathrm{db}$.

Prolonged exposure to noise levels above 75 decibels severely impairs hearing and affects physical and psychological well-being. Noise from vehicle traffic and from ports, airports and railway stations affects health through an increased risk of cardiovascular diseases. Ambient noise is a frequent result of road traffic in urban areas, which is the cumulative result of all noise from vehicles (ranging from 45 to $65 \mathrm{~dB}$ ) affecting quality of life and property values. (Table 1.)

Table 1. Noise levels of different sound sources. (Source: The Issue of Transport and the Environment https://transportgeography.org/contents/chapter4/transpo rtation-and-environment/ [Electronic resource], access free, access date: 01.06.2021.)

\begin{tabular}{|l|l|l|}
\hline Noise level & DB & Cases \\
\hline Extremely loudly & $\mathbf{1 2 0}$ & Aircraft take-off \\
\cline { 2 - 3 } & $\mathbf{1 1 0}$ & Automobile signal \\
\hline Very Loudly & $\mathbf{1 0 0}$ & Metro (Underground) \\
\cline { 2 - 3 } & $\mathbf{9 0}$ & Truck or motorbike \\
\cline { 2 - 3 } & $\mathbf{8 0}$ & Busy intersection \\
\hline Loudly & $\mathbf{7 0}$ & Sound next to the mainline \\
\hline Moderate loudly & $\mathbf{6 0}$ & $\begin{array}{l}\text { Busy street (sound from the } \\
\text { window) }\end{array}$ \\
\hline \multirow{5}{*}{ Weak loudly } & $\mathbf{5 0}$ & Small traffic jam \\
\cline { 2 - 2 } & $\mathbf{4 0}$ & Quiet room \\
\cline { 2 - 2 } & $\mathbf{3 0}$ & \\
\cline { 2 - 3 } & $\mathbf{2 0}$ & \\
\cline { 2 - 3 } & $\mathbf{1 0}$ & Desert \\
\cline { 2 - 3 } & $\mathbf{0}$ & Hearing threshold \\
\hline
\end{tabular}

To reduce the problems associated with noise pollution, a national \#HornFlu campaign has been launched in Delhi. Mumbai and other cities have also followed suit. The awareness campaign was launched at a second meeting between the Indian Medical Association (IMA) and the Mumbai-based non-profit Awaaz Foundation.

The two groups agreed to link the 'Safe Sound Initiative' and the AVAAZ Foundation's 'Get Well sooner' campaign to raise awareness about the harmful effects of noise pollution.

An analysis by the Central Pollution Control Board of India revealed that Mumbai is the noisiest city in the country, with Dr John Panicker, national coordinator of the IMA's Safe Sound Initiative, saying: "Noise causes various health problems related to the heart, mental health and can even lead to cancer. Every organ in our body is negatively affected, but it is the brain that suffers the most

- Water quality. Transport activities affect hydrological conditions and water quality.

- Soil quality. Impacts of transport on soil quality affect the environment, particularly with regard to soil erosion and soil contamination. Coastal transport facilities, such as ports, have a significant impact on soil erosion.

- Biodiversity. Transport also affects biodiversity. The need for building materials and the development of land transport has led to deforestation.

- Land use (land for transport infrastructure). Transport facilities have an impact on the urban landscape. The development of port and airport infrastructure is an important feature of the urban and suburban built environment.

Social and economic cohesion can be disrupted when new transport facilities, such as flyovers and motorways, cross the existing urban community.

Major transportation facilities can affect the quality of urban life by creating physical barriers, increasing noise levels, creating odors, reducing urban aesthetics and affecting architectural heritage.

The expansion of logistical activities has also been an indirect factor in the withdrawal of land in peri-urban and suburban areas.

Naturally, all the above-mentioned areas of environmental impact of transport factors require close attention, control and study, which meet new challenges financial and organizational.

\section{CONCLUSIONS AND RECOMMENDATIONS}

Soft measures to change citizens' public transport behavior. 
One of the measures most welcomed by citizens to encourage them to move away from private motorized transport is increasing the availability of public transport. An extreme measure of this support for citizens is the introduction of free fares for passengers on public transport.

Around the world, more than 100 provide free transport for residents, including Dunkirk in France, Tallinn in Estonia and the entire country of Luxembourg.

An example of how to meet the challenges of both providing free access to public transport and reducing pollution from private car use is Tallinn, which is also known for its narrow, practically unmovable streets in the old city.

Island cities and countries are traditionally notable for their special transport conditions, with Taichung City (Taiwan) offering free rides on all city buses within 10 kilometers. The Malaysian capital, Kuala Lumpur, has established a network of free buses in the central business district in order to reduce the number of private cars.

In China, several bus lines in two cities offer free travel to all, with the number of lines and/or hours of free travel gradually increasing. City authorities recognize their experience as a success and note a significant increase in public transport ridership.

A large number of cities are introducing free city routes linking tourist attractions. In particular, cities in Australia, the USA, France, Poland and Canada. Such measures help make cities more attractive to tourists and increase revenues from the tourism industry.

There are also examples of free public transport services in Moscow, for example, the Moscow metro is usually free on New Year's Eve. There are also fare incentives for metro travel on the busiest lines during early hours to reduce peak loads later in the day. A second significant focus of states' efforts to reduce public transport emissions in the city is the switch to electric buses and other electric-powered vehicles.

Moscow already has a large fleet of electric buses, and their quiet and environmentally friendly operation has a very positive impact on the urban environment. Also, a significant contribution to reducing emissions is made by rail modes of rapid transit, especially the MCC (Moscow Central Circle), a favorite of the city's residents (The Moscow Central Circle (MCC) is a new, fourteenth, overland encircle line of the Moscow Metro. It is 54 kilometers long and has 31 stations. All interchanges between the MCC and the Moscow Metro are free of charge during a 90-minutes ride. The line is equipped with 36 modern trains, which enable rides with a 5minutes interval in peak hours. It takes 90 minutes to take a ride through the MCC with all stops. In Russia this project is the first example of integration of railway and metro in one transportation system.).

\section{AUTHORS' CONTRIBUTIONS}

Conceptualization Zh.M., I.S.; Methodology Zh.M., N.P., I.S.; Official analysis Zh.M., N.A., A.Ts.; Review and Editing N.P., I.S.; Visualization Zh.M., A.Ts.; Control I.S., Zn.M.; Project Administration N.P., I.S.

\section{ACKNOWLEDGMENTS}

The Authors would like to give our thanks to Administration of Plekhanov Russian University of economics for the support of all research projects of the Department of Marketing.

\section{REFERENCES}

[1] G. Timokhina, N. Ivashkova, I. Skorobogatykh, T. Murtuzalieva, Z. Musatova, Management of competitiveness of metropolis public transport in the COVID-19 pandemic based on core consumers' values. In: Journal of Open Innovation: Technology, Market and Complexity, 6(4) (2020) pp. 1-21. DOI: https://doi.org/10.3390/joitmc6040192.

[2] M. Christofi, D. Vrontis, A. Thrassou, S.R. Shams, Triggering technological innovation through crossborder mergers and acquisitions: a microfoundational perspective. In: Technological Forecasting and Social Change, 146 (2019) pp. 148166.

DOI: https://doi.org/10.1016/j.techfore.2019.05.026.

[3] D. Tranfield, D. Denyer, P. Smart, Towards a methodology for developing evidence-informed management knowledge by means of systematic review. In: British Journal of Management, 14(3) (2013) pp. 207-222. DOI: https:// doi.org/10.1111/1467-8551.00375

[4] K. Van De Voorde, J. Paauwe, M. Van Veldhoven, Employee well-being and the HRM-organizational performance relationship: a review of quantitative studies. In: International Journal of Management Reviews, 14(4) (2012) pp. 391-407. DOI: https://doi.org/10.1080/09585192.2017.1345205.

[5] A. Macpherson, R. Holt, Knowledge, learning and small firm growth: a systematic review of the evidence, Research Policy, 36(2) (2017) pp. 172192. DOI: https:// doi.org/10.1016/j.respol.2006.10.001.

[6] D. Tranfield, D. Denyer, P. Smart, Towards a methodology for developing evidence-informed management knowledge by means of systematic review. In: British Journal of Management, 14(3) (2003) pp. 207-222. DOI: https:// doi.org/10.1111/1467-8551.00375. 
[7] M.M. Crossan, M. Apaydin, A multi-dimensional framework of organizational innovation: a systematic review of the literature, Journal of Management Studies, 47(6) (2010) pp. 1154-1191. DOI: https://doi.org/10.1111/j.1467-6486.2009. 00880.x.

[8] R.K. Yin, Case Study Research: Design and Methods, SAGE Publications, Thousand Oaks, CA (1994). https://www.jstor.org/stable/23279888.

[9] L.M. de Menezes, C. Kelliher, Flexible working and performance: a systematic review of the evidence for a business case. In: International Journal of Management Reviews, 13(4) (2011) pp. 452-474. DOI: https://doi.org/10.1111/j.14682370.2011. 00301.x.

[10] Demetris Vrontis, Michael Christofi, Constantine S. Katsikeas, An assessment of the literature on causerelated marketing: implications for international competitiveness and marketing research. In: International Marketing Review, 37(5) (2020). DOI: https://doi.org/10.1108/IMR-07-2019-0202.

[11] Demetris Vrontis, Michael Christofi, Constantine S. Katsikeas, An assessment of the literature on causerelated marketing: implications for international competitiveness and marketing research. In: International Marketing Review, 37(5) (2020) pp. 977-1012(36). DOI: https://doi.org/10.1108/IMR07-2019-0202. 